\title{
INDUSTRIAL DEVELOPMENT PERMITS
}

\author{
D. J. JENKINS *
}

An historical background to the industrial development permit is provided, with a discussion of the procedure necessary for obtaining permits under s.42 of The Oil and Gas Conservation Act.

\section{INTRODUCTION}

In the last few years, Albertans have witnessed the investment of hundreds of millions of dollars in projects designed to upgrade our oil and gas resources. These have enormous effect on the Albertan economy but only a small number of specialists are aware of the statutory steps that must be taken before the first sod may be turned or materials delivered to the project site. Considering the plethora of legislation touching Alberta's energy industry, it is not surprising that few people, outside this small group of industrial specialists, have heard the term "industrial development permit".

The purpose of this paper is to examine the industrial development permit and the requirements of Section 42 of The Oil and Gas Conservation Act which governs the procedure for obtaining a permit. ${ }^{1}$ A review of past applications for such permits will serve as the basis for this investigation.

\section{A. Background}

The agency charged with the administration of The Oil and Gas Conservation Act is the Energy Resources Conservation Board. ${ }^{2}$ In 1974, an amendment to The Oil and Gas Conservation Act gave birth to the industrial development permit. The nature of the creature was then unknown, but the rationale for its creation was stated as follows: ${ }^{3}$

Recent changes in the world's hydrocarbon supply and pricing situation and the relatively secure supply of feedstock in Canada for industrial or manufacturing operations has improved the prospects for the location and operation of large, world-scale petrochemical plants in Canada. Plans for the establishment of petrochemical plants have subsequently emerged across Canada, and particularly in Alberta, which contains substantial hydrocarbon reserves.

Until recent years, the Board played a minor role in controlling the industrial use of gas. It could merely enforce legislation prohibiting the use of Alberta gas in Alberta until particulars had been filed with it. Drilling, enhanced-recovery, lighting, and fuel usages were exempt from this requirement. The Board also had limited authority to control gas use to avoid waste.

When petrochemical manufacturers began announcing plans to locate their projects in Alberta, the provincial government developed a policy to achieve the best use of Alberta's hydrocarbon reserves. It required certain gas users to obtain industrial development permits 80 that the natural gas would be used appropriately by industry in Alberta, and major industries would develop in orderly fashion. Accordingly, The Oil and Gas Conservation Act was amended in 1974 to specify that no gas or gas product produced in Alberta was to be used in the province as a raw material or fuel in the production of carbon black, ammonia, urea, ethanol, methanol, or any petrochemical product, unless permitted by the Board.

Similarly, in 1975 the government amended The Coal Conservation Act, prohibiting the use of Alberta coal or its products as a raw material, reductant, or fuel in any industry, unless the Board had granted permission.

* B.A., LL.B. with the firm of Stephen, Ebbert, Olien of Calgary, Alberta.

1. The Oil and Gas Conservation Act, Revised Statutes of Alberta, 1970, Chapter 267, as amended.

2. Hereinafter referred to as "the Board".

3. Conservation in Alberta 1975, Energy Resources Conservation Board, Calgary, Alberta, March 1976, at 4. 
In 1976, The Oil and Gas Conservation Act was further amended so that no energy source could be used as a raw material or fuel in any industrial or manufacturing operation unless the Board granted an industrial development permit authorizing such use. The full text of Section 42 is set out in Attachment ' 1 ' of Appendix " $A$ " to this paper."

The full importance of this Section is not immediately apparent. As explained in the Board's interim directive ID-OG 77-1, industrial development permits are not restricted to the production of carbon black, ammonia, urea, ethanol, methanol and petrochemical derivatives but include such industrial operations as cement plants, pulp and paper mills, refineries and the like. ${ }^{5}$ In other words, if a project requires the use of oil or gas in its process, it will also require an industrial development permit, either now or in the future.

It should also be pointed out that The Coal Conservation Act contains provisions requiring an industrial development permit where coal in excess of 250,000 tons per year is used in an industrial or manufacturing operation. However, since no application has been filed for the industrial use of coal, consideration of a coal based industrial development permit has been omitted. It is submitted that the general principles and concerns respecting gas based industrial development permits will be applicable to those based on coal. ${ }^{6}$

The June 6, 1974 cut-off date for projects qualified for exemption under Section 42 of The Oil and Gas Conservation Act resulted in very few industrial projects acquiring that privilege. ${ }^{7}$ Similarly, the Board has heard relatively few applications for industrial development permits but, it is submitted that a review of these reports is mandatory for any person contemplating an application to the Board for an industrial development permit. $^{8}$

Proceedings before the Energy Resources Conservation Board are governed by Part 6 of The Energy Resources Conservation Act. The applications procedure may be summarized as follows:

(a) The application and supportive documents are filed with the offices of the Energy Resources Conservation Board.

(b) Copies are sent to Business Development and Tourism and to the Departments of Environment and Energy and Natural Resources.

(c) The Board staff reviews the application to ensure it is complete and requests additional information by way of deficiency letter if it is not.

4. The references in s. 42(2.1)(a) to ss. 38 and 43 of The Oil and Gas Conservation Act are unimportant to this investigation. Section 38 deals with schemes for enhanced recovery, concurrent production, and gathering, storage and disposal of oil and gas while s. 43 relates to Oil Sands projects. Under s. 1(1) 10 of the Hydro and Electric Energy Act, R.S.A. 1970,c. 49, as am., "Power Plant" means "the facilities for the generation of electrical energy from any energy source".

5. See Section '2' of Appendix " $A$ ", infra.

6. Further reference to Coal Development may be had to A Coal Development Policy for Alberta, Government of Alberta, Department of Energy and Natural Resources, June 15, 1976.

7. See Appendix " $B$ ". Appendix " $B$ " is a table produced by the Board in its report 75-N, at page 1-5, which shows which projects are exempt from the requirements of an industrial development permit.

8. The Board has issued a number of reports respecting industrial development permits. The full citations for these reports are contained at Appendix " $C$ " and the abbreviations used by the author are cross-referenced as well. 
(d) If the project proposed in the application is minor in nature, the Board is free to consider the application at once and without public involvement; if it is major, the Board may publish Notice calling for submissions at a public hearing of the matter. Such Notices are published in the local press and sent to the government, elected representatives and business interests.

(e) At the hearing, the Board considers the views of the applicant and others who have filed submissions and appraises the application in accordance with certain policies and criteria which form the subject matter of the balance of this paper.

(f) The Board then analyses the application in light of evidence given at the hearing and prepares its recommendation in report form. This report is submitted to the Lieutenant-Governor in Council, concerned governmental departments and Cabinet. Any permit granted by the Board is subject to the terms and conditions set out by the LieutenantGovernor in Council in his approval. ${ }^{9}$

\section{B. Purpose of Article}

From this brief introduction, it should be apparent that an application for an industrial development permit is a large and complicated undertaking. It is also very costly. Engineering and planning studies alone may run into hundreds of thousands of dollars and a deficient application may result in delay or denial of a permit. For these reasons, industry and counsel must be aware of the requirements for an industrial development permit and must appreciate the nature of the Board's concerns in hearing such an application. Accordingly, the balance of this article will attempt to outline these requirements and concerns in light of the Board's Decision Reports issued to date.

At this point, the writer should issue the standard caution: the opinions and observations made herein are solely attributable to the writer and he takes the responsibility for any errors, omissions or inaccuracies. Further, any comment or editorial remark respecting the treatment of applications is that of the writer and in no way reflects the internal and confidential treatment of applications by the Energy Resources Conservation Board.

\section{THE REQUIREMENTS AND CONCERNS}

Section 42 of The Oil and Gas Conservation Act and attachment II to the Board's Interim Directive ID-OG 77-1 outline the main areas of concern to the Board in an application for an industrial development permit. In Report 75-F, and in each of the Board's subsequent reports respecting industrial development permits, these concerns have been formalized under the heading "Definition of Issues". ${ }^{10}$ The issues outlined in the reports coincide with the headings used by the author in Section 2 below. ${ }^{11},{ }^{12}$

9. Conservation in Alberta, 1975, at 5-6. See also Appendix "A" post .

10. See Appendix " $C$ ", infra.

11. 75-F, pp. 4-1 to 4-3:

Section 42 of The Oil and Gas Conservation Act provides that the Board shall not grant an industrial development permit "unless in its opinion it is in the public interest to do so, having regard to, among other considerations,

(a) the efficient use without waste of gas or gas products, and

(b) the present and future availability of hydrocarbons in Alberta." 


\section{A. Matters of Particular Importance to the Board \\ 1. The Present and Future Availability of Hydrocarbons in Alberta}

Predicting the present and future availability of hydrocarbons in Alberta is very similar to predicting the weather in this province: it is uncertain at best. However, the Board is specifically prohibited by statute from granting an industrial development permit unless it can be shown that there are sufficient hydrocarbons available to make such issuance in the public interest. ${ }^{13}$

The Board believes that matters affecting the public interest in the use of gas or gas products may be divided broadly into two categories. The first category would include the matters specified under (a) and (b) above and any other matters which the Board would consider critical to its appraisal of an application for an industrial development permit, and respecting which the Board believes it is a competent and appropriate body to weigh evidence, study, and formulate definite conclusions. The second category would include other matters which would be important to the Lieutenant-Governor in Council in his review of an application following consideration of it by the Board, but which would not be critical to the Board's own appraisal or concerning which the Board would not itself formulate definite conclusions.

The Board finds the following to be the main matters in the first category and therefore the main issues for it to deal with in appraising the applications before it: the determination of whether the proposed use of gas or gas products would be in the public interest having regard to

(a) the present and future availability of hydrocarbons in Alberta (item (b) of Section 42, Subsection (5) of the Act);

(b) the efficient use without waste of gas or gas products (item (a) of Section 42, Subsection (5) of the Act);

(c) the possible use of alternative sources of raw materials or fuel;

(d) the degree of resource upgrading which would result; and

(e) the economic impact on Alberta.

With respect to each of the above matters the Board considers it appropriate, not only to weigh and analyse the relevant evidence but also to make any study which may be necessary to determine the effect of the matter on the public interest.

In the second category, that of matters of broad interest, the Board believes the following are probably the most important:

(a) the requirements of gas and the arrangements for the acquisition of the gas or gas products;

(b) the prices to be paid for the gas;

(c) the plans for the marketing of the products;

(d) the adequacy of the technical, marketing, and financial background of the applicants;

(e) the plans for the financing of the proposed projects;

(f) opportunities for government or public participation in the projects;

(g) the proposed location of the projects;

(h) the management and control of the projects;

(i) the manpower requirements;

(j) any government support required;

(k) the social impact resulting from the projects;

(1) the environmental impact;

(m) the status of other authorizations required; and

(n) related industrial development.

With respect to the matters in the second category the Board will report the position of the applicants, and views expressed by intervenors and, where it may have views of its own, the Board will also offer its comments.

By including matters such as the social and environmental impact in the second category the Board does not intend to imply that such matters are of secondary importance.

12. To the list of issues under Section 2 hereof the author has taken the liberty of adding two procedural matters, the term of the permit and assignment of permits, as they are discussed in all reports.

13. S. 42(5), The Oil and Gas Conservation Act. 
"Public interest" in this context can fairly be stated to mean "the Alberta public interest". ${ }^{14}$

Applicants for an industrial development permit must include in their application a year by year forecast of the quantities of each of the raw materials and fuels required for the proposed project and a statement respecting the flexibility of the project to use alternative raw materials or fuels. ${ }^{15}$ Additionally, applicants have generally supplied a year by year forecast of their estimate of the availability of hydrocarbons together with a sample deliverability and future requirements study. While there is no special format to be followed in presenting information of this nature, the applicant must be prepared to justify its use of the quantity of hydrocarbon requested and to show that there are sufficient reserves of that hydrocarbon available, after taking their proposed share, to meet the Alberta 30-year demand.

The Board's first two reports, Report 75-F and 75-F-A, focused on the problem of calculating present and future availability of hydrocarbons. The issues raised in Report 75-F concerned the Board's whole method of calculating reserves and prompted the following comment: ${ }^{16}$

Canadian Western Natural Gas Company Limited and.Northwestern Utilities Limited, in commenting on recent applications to remove gas from the Province, have suggested that the Board review its present procedures regarding the determination of provincial surplus. Partly as a result of these representations, the Board, in its recent decisions respecting the removal of gas from the Province, concluded that it would be in the public interest to exercise caution in granting new permits or amending existing permits until any uncertainties respecting the availability for immediate contracting of the volume of gas indicated by the surplus calculations had been resolved.

As a result of this uncertainty in gas supply, the Board, in June of 1974, reopened a public hearing held in 1972 to consider the future requirements of the province. The resultant Report, 74-W, ${ }^{17}$ contained a year by year forecast of gas supplies to the year 2004 and an illustrative deliverability schedule of these reserves. The Board concluded, in Report 75-F, that there was no public interest reason associated with the availability of gas for refusing the requested permits because its forecast of the production from proved and future reserves indicated that adequate reserves are and will be available to meet Alberta's future requirements. ${ }^{18}$ The Board did caution however that, in calculating the 30 year requirements, it did not consider pending applications for permits for the production of fertilizer nor did it make allowance for

14. It may be implied that the "public interest" protected by the Board is Alberta's public interest first and the Canadian public interest second. For example, at 6-4 of Report 77-C the Board states:

With respect to the use of pentanes plus as a refinery feedstock elsewhere in Canada, the Board believes that such use would not be more in the Alberta public interest than would the upgrading within the Province.

15. Interim Directive ID-OG 77-1, see infra., at 2 of Attachment II, Appendix " $A$ ".

16. Report 75-F at 5-3 to 5-4: The "recent decisions" referred to are:In the Matter of an Applica. tion of Alberta and Southern Gas Company Limited Under The Gas Resources Preserva. tion Act, ERCB Report 75-A, January 1975, and In the Matter of an Application of Canadian-Montana Pipeline Company Under The Gas Resources Preservation Act, ERCB Report 75-B, January 1975. Addenda - Controversy surrounding Alberta's "gas bubble" and the advisability of permitting further exports to United States markets in the fall of 1978 demonstrate the continuing difficulty in estimating the Present and Future availability of hydrocarbons. Future reference may be made to transcripts of the National Energy Board hearings held in Calgary, Alberta in October of 1978.

17. Appendix to Alberta's Requirements of Energy and Energy Resources, 1975-2004, March 1975.

18. Report 75-F, at 5-12 to 5-13. 
the development of substitute natural gas from coal, which was considered to be a realistic alternative to natural gas reserves by the mid-1980' $\mathrm{s}^{19}$

On November 1, 1975, the National Energy Board announced that the border export price for natural gas would be $\$ 1.60$ per MCF and, shortly thereafter, the Federal and Provincial governments indicated that within a few years the Canadian oil price would approach parity with international oil prices. This, together with the Alberta government's decision to set the Toronto city gate price at $\$ 1.25$ per MCF, prompted the Board to request that the Lieutenant-Governor in Council delay any action on Report 75-F until it had the opportunity to re-assess the viability of the proposed fertilizer plants. Report 75-F-A reexamined the economics of the proposed projects and recommended to the Lieutenant-Governor in Council that he may wish to condition any permit such that the permitee would have to satisfy the Minister of Energy and Natural Resources, by some appropriate date, with respect to the price to be paid for the gas to be used in the project and with respect to the price of ammonia to be shipped to export markets. ${ }^{20} \mathrm{This}$ condition was suggested, it is submitted, because the incremental benefits to the Province from the proposed projects were less than one-half of those estimated by the Board in Report 75-F. ${ }^{21}$ Indeed, the Board concluded that it was unlikely that the projects would proceed as separate ventures if the cost of gas were based on full field value rather than the implied value of gas under the applicant's control. ${ }^{22}$

In all the Reports under examination, the determination of future hydrocarbon availability is closely allied to the provincial economic impact of the project. While this relationship will be considered in greater detail below, it is interesting to note the rather arbitrary tests employed by the Board in determining economic impact and reserve depletion. The Board's comments with respect to the latter have been: ${ }^{23}$

In determining the volume of future gas which would be used to meet Alberta's requirements, the

Board has assumed that all currently proved gas reserves would first be produced at the maximum possible rate and only then would future reserves be used to meet Alberta's requirements. The Board recognizes that this is an arbitrary assumption and actual production would not occur in this manner. With respect to production to meet new removal permits, the Board has assumed that the 30 year protection policy will continue in the future. The Board assumed that certain volumes of gas would be authorized for removal in the future in stages until a surplus no longer exists ... the assumptions regarding production to meet Alberta's requirements and future removal permits have the effect of limiting considerably the production of gas from future reserves.

To determine the general economic impact of a project, the Board compares the benefits which would result from selling the volume of gas in extraprovincial Canadian markets with the benefits which would result from using the volume of gas requested in the applied-for project. ${ }^{24}$ Consideration is also given to export market price of both the hydrocarbon and final product should it be relevant to the application. ${ }^{25}$ In short, the Board employs the methods of first-in, first-out (FIFO) and comparative markets to deter-

19. Id., at 5-7 and at 5-12 to 5-13.

20. Report 75-F-A, at 4-1.

21. Id., at 3-2.

22. Id., at 3-3.

23. Report 77-C, at 6-7.

24. Report 75-F-A, at 3-1. See infra, for further discussion of assessment of a project's economic impact.

25. Id., at 3-2. 
mine whether there are sufficient volumes of gas and whether or not a project is economically advantageous.

The problem of determining present and future availability of hydrocarbons in Alberta is compounded when one must determine the availability of a specific hydrocarbon. A number of the Board's Reports have dealt with the specialty problems of the availability of natural gas reductants such as ethane and pentanes plus. ${ }^{26}$ While the Board's method of calculating availability of these products is essentially the same as described above, certain refinements have been required. Prior to 1973 for example, the Board did not report on either proved reserves of ethane or on the volumes of those reserves but chose, rather, to include them in its gas reserves forecast. In its Report 75-N, the Board for the first time calculated reserves of ethane and expressed the intention to continue to do so on a yearly basis. Its method may be summarized as follows: ${ }^{27}$

For its appraisal of the present and future availability of ethane, the Board first compared the year by year requirements for ethane of existing and proposed petrochemical facilities with the year by year forecast of ethane practically recoverable from Alberta's market gas. It also compared the total requirements of the existing and proposed plants with the total recoverable ethane reserves over the proposed permit term.

The question of what is "practically" recoverable from market gas is open to broad interpretation. When faced with the problem of declining recoverable rates of pentanes plus from proven fields, neither the Board nor interested parties could agree on an estimated rate of recovery decline ${ }^{28}$ The Board was forced to re-assess its estimate of recoverable rate from both proved and future gas reserves and assumed that a pentanes plus yield of 15 barrels per MMCF of marketable gas would prevail over the near future whereas the actual recovery ratio at that time was closer to 20 barrels per MMCF. This assumption considerably limits the estimated gas available for production from future reserves. ${ }^{29}$ As a result of this assumption, the Board concluded that: ${ }^{30}$

... the figures show that, only if the use of pentanes plus as a natural gas liquids buffer and for blending with heavy crude oil is discontinued, and if a significant portion of the pentanes plus not available in the Edmonton area is made available in the future would there be sufficient feedstock for even one of the proposed projects.

The effect of this shortage is that the Board has been forced to choose one project as the best use of the available supplies of pentanes plus and compare all other proposed projects to it. The following extract from Report 78-C demonstrates the Board's rather uncertain use of its discretion: $:^{31}$

26. Reports 75-N ethane, 76-B ethane, 76-E methanol, 77-C pentanes plus to produce benzene, 77-H pentanes plus, 78-C pentanes plus.

27. Report 75-N, at 7-15.

28. Report 77-C, at 6-7. See also Report 78-C at 5-2 to 5-4 where Gulf Oil Canada Limited submitted that 22 barrels per MMCF would be available in 1977 and the yield would then decline to 20 barrels in 1985 and 15 barrels in 1995 . Further, it was submitted that, reserve additions of gas would add 10 barrels per MMCF in 1977 increasing to 15 barrels during the period 1982 to 1985 as a result of richer gas coming on stream. The Board however affirm. ed its own study of availability of pentanes plus to the year 2000, as set out in Report 77-C with the caveat, "... that recent and current growth rates of gas reserves could make the forecast somewhat lower in the middle and later years".

29. Report 77-C, at 6-7. Page 6-6 of their Report contains a summary of the data and method by which the Board calculates both proved and future reserves of natural gas.

30. Report 77-C, at 6-4.

31. Report 78-C, 1-2. 
Even though it has not assessed the relative priorities of certain pentanes plus uses in detail, the Board believes that manufacture of benzene represents greater upgrading of pentanes plus than production of gasoline and diesel fuel, and should therefore have a high priority. The Board is of the view that, if the permit is issued to Petalta and the benzene project proceeds, there may be sufficient pentanes plus available to both projects for the permit term requested by Gulf. The Board believes that sufficient pentanes plus would be available to both projects only until the end of 1981 , and therefore is prepared to include and permit the volumes requested by Gulf for the period 1 January 1979 to 31 December 1981.

While admitting that the Board has not fully assessed the priority of projects requiring pentanes plus as a supply, the Board has commented that, ". . . should it be necessary to allocate available pentanes plus supplies, careful consideration would have to be given to the relative benefits of each requirement and availability of alternatives. ${ }^{\text {"32 }}$ In the case of pentanes plus, the "availability of alternatives" refers to the possibility of fractionation of heavy crude oil or synthetic crude oil and the use of naphtha or other light end oil products as a natural gas liquids buffer and commingling agent for synthetic crude oil.

By way of summary it can be said that there are three main problems in attempting to calculate the present and future availability of future hydrocarbons in Alberta. First, forecasts are merely educated guesses and are subject to interpretation. Any forecast must be thoroughly documented but the task is made difficult by lack of accurate information due either to confidentiality or insufficient market data. Second, the availability of specific hydrocarbons is a compound problem in forecasting in that factors, such as local availability, extraction and recovery techniques and alternative uses of the hydrocarbon are brought into play. Third, the economic and political climate of the province must be gauged. In this regard, one need only mention that the fertilizer projects which were the subject of the Board's first number of Reports have yet to receive the approval of the Lieutenant-Governor in Council.s3

\section{The Efficient Use Without Waste of}

Hydrocarbons and Hydrocarbon Products

Under this topic of inquiry the Board examines the process details for the proposed project. Applicants for an industrial development permitmust submit, among other things, the following types of information in support of their application: ${ }^{34}$

A description of the products to be produced and the processes involved in the proposed project, together with flow sheets, material balances and energy balances. Also, measurement details relating to energy resources to be delivered to the proposed project and any emissions to the atmosphere of portions of the energy resources. (The description of products should include reference to anticipated minor changes in product runs which might occur from time to time.)

Applicants rarely have difficulty presenting these details since comprehensive engineering studies and plans are drawn for a proposed project prior to making an application to the Board.

To ensure conservation and effective use of energy resources, the Board examines the technical process in detail and compares it with proven practices, the state of the art and theoretical process energy balances.For example, in Report 75-G, an application to use natural gas for the production of anhydrous ammonia, the Board made reference to recent technical literature

32. Id., at 5-5.

33. See Reports 75-F, 75-F-A and 75-G. This was the situation as June 1978.

34. ID OG 77-1, Attachment 2. 
to determine whether or not a 15 to 20 per cent increase in fuel gas was a substantial deviation from theoretical design capacity of the proposed plant. ${ }^{35}$ While the Board found the proposed process up-to-date technically, in terms of the efficient use of raw materials, fuel, water and electricity, it was not satisfied that the boiler was efficient in its use of fuel and feedwater. Accordingly, as a condition of any permit, the Board required that the applicant provide evidence that this inadequacy had been corrected before final design was completed. ${ }^{36}$

The Board's watch-word appears to be "balance". Heat transfer balances, stream energy consumption balances, electrical, water and evaporation rate balances, over-all energy requirement balances and final product energy consumption balances are all examined and any discrepancies must be explained. Even where an energy loss is unavoidable, as in the case of heat loss through cooling towers, the Board expects the loss to be minimized when technically and economically feasible. ${ }^{37}$

For all but those of engineering background, the technological details are dreary and incomprehensible. However, the impression should not be left that, when the Board examines the technical process details, it does so in a vacuum. In Report 77-C, an application to process pentanes plus to benzene, its by-products, gasoline and diesel fuel, the Board was cognisant of the fact that coal could be used as a feedstock for the process but had been abandoned as a non-viable process in other countries ${ }^{38}$ The efficient use of hydrocarbons is of primary concern to the Board but such use is necessarily contingent on such factors as feedstock supply, market conditions, technological advances and the importance of the final product. ${ }^{39}$

\section{The Possible Use of Alternative \\ Sources of Raw Materials or Fuel}

Hydrocarbon-based industries, by their very nature, are restricted to the use of a limited number of fuels or feedstocks. Natural gas, oil, synthetic crude oil, coal and coal reductants are the only choices available. With declining long-term reserves of natural gas and oil, attention is turning increasingly to the possible use of synthetic crude oil and coal, or its derivatives. Consequently, the Board's investigation of alternative fuels, in projects proposed to date, has centred on the technological and economic feasibility of using these substances.

In Report 75-F, the Board concluded that both coal and oil were viable but unattractive alternatives to the use of natural gas for the production of anhydrous ammonia: 1041

35. 75-G, at 5-25.

36. Id., at 5-26.

37. See Report 75-F, at 5-20, for example.

38. Report 77-C at 6-42.

39. The efficient use of hydrocarbons in a proposed process remains but one of the factors employed to assess a project's priority. In Report 77-H, for example, the proposed project clearly had the advantage of being more efficient than other similar projects but the Board was concerned that the applicant did not have an established pentanes plus feedstock supply. Accordingly, the Board conditioned the permit such that the applicant must, prior to the commencement of plant construction, satisfy the Board of its feedstock security, at 6-34.

40. Report 75-F, at 22.

41. Id., at 5-23. 
On the basis of its investigation of the matter, a review of available literature, and the evidence submitted at the hearing, the Board agrees with the applicants that with the relative prices for gas, oil and coal prevailing today, the economics of producing ammonia favour the use of gas. However, in view of the anticipated upward trend in the price of coal, the Board is of the opinion that the possibility of using coal as a feedstock and fuel for ammonia production should be re examined in the future. The Board does not believe that the economics of using oil as a feedstock or fuel will improve greatly over the situation prevailing today, and therefore does not expect it to become a practical alternative in the future.

In addition to the future possibility of building new ammonia plants to use coal as feedstock and fuel, the Board believes that, at some time, the conversion of existing plants from gas to coal may become practical and may be in the public interest. An analysis carried out by the Board suggests that, given the relative gas and coal prices which the Board expects in the future, the conversion of gas-based am. monia production plants to coal might be economically feasible even with as little as 8 to 10 years of useful life remaining for the facilities ... . another possibility would be to build a very large substitute natural gas plant appropriately located in the province to serve ammonia manufacturing plants and generally to supplement the total gas supply in the province. The Board cannot appraise these alternatives at this time but it believes that these possibilities, and others, should be considered at ap. propriate intervals during the life of projects manufacturing ammonia from gas.

As the reader will note, an important factor in the investigation of possible use of alternative fuels is whether or not plant design is capable of taking a different feedstock or fuels. In Report 75-N, the Board observed that considerable research is being directed towards the production of synthetic fuels from coal and the possible applicability of such a process to the production of ethylene and ethylene derivatives. However, it further concluded that, in light of technological changes and the length of time and capital outlay required to convert an ethylene plant to the use of synthetic coal fuels, the over-all economics of such an undertaking would not justify the Board's requiring such a design change to be made. ${ }^{42}$

Report 76-E, an application to use natural gas as a feedstock and fuel for the production of methanol, illustrates the Board's very real concern for the use of alternative sources of raw material and fuel: 4344

... the applicant made it clear that it had no intention of further considering a coal-based plant at this time, the Board believes that this matter is not only pertinent to disposition of the subject application, but also of direct importance for future petrochemical developments in Alberta. Of critical importance in this section is consideration of whether the proposed gas-based facilities would impinge on the future development of coal-based methanol plants.

The Board does not now have before it an application to construct a coal-based methanol plant nor is such an application expected in the near future. Recognizing the lead time normally associated with processing of an application through regulatory approval, engineering design and construction scheduling, the Board does not anticipate that any coal-based facility could be placed on production before 1983. Having regard for market uncertainties, it further believes that commercial coal-based facilities are unlikely to be in production in Alberta before 1985. Should the new methanol supplies in the Middle East and U.S. not develop, there would appear to be an opportunity for Canadian production, based on coal as a feedstock, to supply a greater portion of the export market. Conversely, if large methanol productive capacity is developed in the early 1980 's in the Middle East or other potential areas of production, it could greatly reduce the market prospects for an Alberta plant.

The Board concluded that the application should be considered on its own merits as the development of a coal-based methanol plant in Alberta would be primarily dependent on the availability of export markets. However, in approving the application the Board issued the following stern warning: ${ }^{4}$

It expects the current application to be the last request to use gas for this purpose; and the application can indeed be viewed as the final stage in the development of a methanol complex that commenced before the enactment of industrial development permits. Its approval would therefore not set any precedent.

42. Report 75-N, at 7-42.

43. Report 76-E, at 5-32.

44. Id., at 5-33.

45. Id., at 5-34. 
Total conversion of an operation from one fuel source to another is not the only alternative considered by the Board. Serious consideration is given to the use of alternative fuels in the various component stages of an over-all complex. For example, it may be more economic, in the Board's view, to use oil-fire heaters at one stage of a plant's operation or, similarly, a coal-fired steam generator may be more attractive than one using natural gas as a fuel source. In short, the Board seeks economically viable and technologically feasible fuel source alternatives to minimize the depletion of our short-term, non-renewable resources.

\section{The Degree of Resource \\ Upgrading Which Would Result}

The object of the Board's investigation in this area is to ensure that hydrocarbons are upgraded to the greatest possible degree. The method used to assess the proposed degree of upgrading is similar to that used to assess the present and future availability of hydrocarbons in Alberta: the benefit accruing to the province from sale of equal volumes of gas in extra-provincial markets is compared to the benefit accruing to Albertans from processing within the province.

This "alternative use" test is explained by the Board in Report 77-C, an application to employ pentanes plus for the production of benzene and its derivatives: 16

One simple test frequently used to determine whether a project is in the public interest is to compare the value of the products produced with the cost of the feedstock and fuel used directly in its production. In this case to measure the degree of upgrading of each project the value of products including benzene would be compared to that of the pentanes plus used in their manufacture. Such a comparison can give only a very crude measurement of the degree to which the project benefits the province since it ignores the alternate value of other inputs used in manufacture such as labour and materials. However, the degree of upgrading may have some directional economical value, and therefore the Board has calcualated upgrading ratios, the ratios of the product value to feedstock value, for each of the projects.

This comparison is generally done on a direct dollar comparison basis. For example, if the value of the volumes of gas to be used in the proposed project is 600 million dollars and the upgrading process would result in a product or products worth 900 million dollars, the upgrading ratio is 1.5 in favour of the upgrading.

Evaluation of the degree of upgrading is also related to the usage priority of the hydrocarbon attributed it by the Board. An example of this is pentanes plus. The Board has given a higher priority to the manufacture of benzene from pentanes plus than for the production of gasoline and diesel fuels. ${ }^{47}$

\section{The Economic Impact on Alberta}

The Board's interim directive, ID-OG 77-1, requires that applicants for an industrial development permit submit the following information under this heading: 48

Detailed evidence of the impact of the proposed project on the Alberta economy, categorized as theimpact of the project itself and that resulting from expected downstream development, including the impact of capital and operating expenditures for labour, services, materials and supplies, payment of taxes and royalties, and incorporating any appropriate economic multiplier effect. In certain circumstances the Board may require a cost benefit analysis.

A summary statement of the over-all desirability in the Alberta public interest of the proposed project.

46. Report 77-C, at 6-83.

47. Report 78-C, at 5-5.

48. See Appendix " $A$ ", infra. 
It will be noted that these rather broad informational requirements overlap somewhat with the issues under the heading "Materials of Broad Interest", below. However, to the extent possible, only matters of critical economic importance will be dealt with here.

The Board employs two tests to evaluate the economic impact of a project on the province: 19

The Board has outlined previously, in ERCB Report 75-F, that one means of measuring the economic impact on the province of proposals . . . is to compare the benefits from the proposed project to the benefits from selling the same volume of gas in extra-provincial markets. The Board also recognizes that a second test could be applied which would compare the benefits that would be obtained from the proposed project with those obtained from other possible processing operations which would use gas as a raw material and fuel .... A second test is meaningful only when an alternative use would be precluded if the proposed use were authorized. Where hydrocarbon availability and other circumstances would permit both a proposed project and the alternative, only the first test is appropriate.

The Board's method of applying this second test is outlined in Report 77-C. Further, this same report indicates that the Board is willing to equate the direct economic impact of a project with its indirect or tertiary economic impact. $^{5051}$

49. Report 75-G, at 5-40.

50. Report 77-C, at 6-81 to 6-82. For similar comments see Report 75-N, at 7.58 and Report 76-E at 5-21.

In general, the incremental economic impact of each project is equated to the sum of those revenues from the project which Albertans would otherwise not receive if the project were not implemented. The Board notes that a large development such as that proposed by the two groups of applicants would probably employ manpower and use materials which would find productive use even if the project did not proceed. As a result the incomes provided by either applicant may well not be incremental to the Alberta economy, since it is likely that most suppliers of the project, and most construction and operating workers employed by the project would find employment and receive incomes in any event. Accordingly, the Board acknowledges that the project may have a negative impact on other projects and production in Alberta. However, the Board believes that migration of manpower and capital equipment into the province would make this negative impact small. For simplicity it has arbitrarily assumed that all capital and operating expenditures in Alberta would have a net incremental impact on Alberta income levels.

For this purpose of comparing the two proposals the Board believes a further test evaluating the net benefit of the projects to Alberta is appropriate. As a measure of the net benefit to Albertans arising from the project the Board has calculated the share of project cash flow accruing to Albertans, the corporation income taxes accruing to the Alberta government, and taxes accruing to Alberta municipalities. To calculate the project cash flow, the Board deduced from its forecast of annual revenues the estimated cost of capital (in the form of outlays for equity and retirement of debt), operating costs, interest charges, feedstock costs, and federal, provincial, and local taxes. The Board then discounted the Alberta net benefit (the sum of the project cash flow plus Alberta corporation income taxes and municipal taxes) at a real rate of 10 per cent per annum to reflect the value of capital employed in some alternate use. The resultant present worth represents the net benefit of the project to Alberta. The Board believes this represents the best means of comparing the relative merits of the two projects.

The Board has not included as a benefit to Albertans any monies paid to governments outside Alberta, including the Government of Canada. To the extent that increased payment of federal corporation income taxes may result in an increase in the services provided by the Government of Canada to Albertans, the Board's estimate of benefits will be understated. At the same time to the extent that the location of a project in Alberta will result in increased demand for provincial and local government services, inclusion of the entire amount of taxes paid to these governments as a net benefit to Alberta would be an overestimation.

51. In Report 77-C, at 6-85, the Board commented in this regard:

The Board notes that certain estimates of the indirect impact of a project suggests that it is somewhat smaller than the direct impact with the most common estimate being about 70 or 80 per cent. Upon reviewing this matter, the Board believes that such a lower ratio may be a reasonable reflection of the average indirect impact for Alberta over the past period and into the middle term future. The Board has assumed, however, that as the economy of Alberta develops and more and more goods are produced and purchased within Alberta, the value of this multiplier may increase ... 
Calculation of the economic impact of a proposed project is obviously a many faceted and complex problem. However, a detailed analysis of the Board's methodology in this regard would serve little purpose here and the reader is directed to Appendix " $\mathrm{D}$ " of Report 75-F should such an examination be of interest.

B. Matters of Broad Interest

1. The Requirements of Hydrocarbons and the Arrangements for the Acquisition of Hydrocarbons or Hydrocarbon Product

The purpose of the Board's investigation under this heading is to assure that an applicant has a sufficiently stable hydrocarbon supply to ensure success of the project. Factors examined include: peak and average day requirements of the project, location of the hydrocarbon, ultimate and proven reserves, transportation facilities, yearly production and revenue forecasts and alternate sources of feedstock or fuel.

Applicants who control the source of their feedstock or fuel supply tend to be in a somewhat better position than those who do not. However, the Board realizes that not all applicants are so fortunate: ${ }^{52}$

The Board does not consider it essential that an applicant for an industrial development permit own or have under firm contract the gas required for the total term of his project. However, where arrangements have been made for the acquisition of gas, the Board wishes to be informed of them. If an industrial development permit is issued to a party that has not completed satisfactory arrangements for its supply of gas, the Board would include as a condition in the permit that the permitee satisfy the Board prior to the project start-up date of the plant as to the arrangements that have been made for the supply of most of the necessary gas for the project.

A description of the arrangements for the acquisition of hydrocarbons is part and parcel of the applicant's analysis of the present and future availability of hydrocarbons.

When an application is made to the Board for an industrial development permit, one problem facing applicants is that they cannot accurately assess hydrocarbon requirements for an in situ plant when the structure is only at a design stage. The Board has shown some sympathy for this problem: ${ }^{53}$

The Board believes it appropriate to include in any industrial development permit, limitations to the volumes of gas which may be used as raw material and fuel .... The Board recognizes the need for some flexibility in the operations of a project and believes that there should be provision for some excess over the expected gas consumption.

This willingness to allow some flexibility in requested volumes of hydrocarbon is, however, conditional upon adequate supplies of the hydrocarbon being available. In the case of pentanes plus, for example, expected shortages require that the Board take into consideration project priorities when evaluating an application which requests the usage of pentanes plus.

\section{The Prices to be paid for Hydrocarbon}

Comment under this heading is unnecessary as the factors considered by the Board overlap with and are discussed in Part A, Subsection 1, supra, and the section immediately following.

\section{The Plans for Marketing of the Products}

The Board requires that an applicant submit the following information respecting its market plans: ${ }^{34}$

52. Report 75-F, at 6-6.

53. Id., at 6-7.

54. See Appendix " $A$ ", Attachment '2', Paragraph (n). 
A general statement of marketing plans, including the location of intended markets, the method of transportation thereto, a projection of market prices for the products to be produced and a discussion relating to the marketing plans to the over-all Alberta, Canada, North America, and world supply and requirements situation.

Information typically filed in support of this aspect of an application includes a discussion of long- and short-term contract commitments, details of options, the existence of "take or pay" and other contractual provisions, long. and short-term supply/demand trends and a statement concerning the use of the product within Alberta and its availability to Albertans from the proposed project. Should information of this nature be omitted from an application, the Board may makeits own estimate of likely market distribution if deemed relevant to its decision. ${ }^{.5}$

\section{The Adequacy of Technical, Financial and \\ Marketing Background of the Applicant}

Anyone proposing to build an industry of the scale of the proposed projects must be able to sustain the project, once started. Failure of a project could have an adverse economic impact on the Alberta public interest. Accordingly, the adequacy of the technical, financial and marketing background of the applicants must be considered.

To satisfy this requirement, applicants usually submit with their application a balance sheet, annual report and summary of the company's history and activities. The company's past commercial ventures, its ownership, related holdings, staffing, cash flow and marketing experience with the proposed or similar products are usually discussed. If specific financial arrangements have been made, a copy of the contract, bond or debenture may be included. In the matters reported on by the Board to date, there has been little comment or discussion relating to this type of information and, it is submitted that the Board will give little weight to such evidence unless the project is of marginal viability or the applicant of dubious background or ability. 5. Plans for Financing the Proposed Project

As in the preceding section, an examination of past Board reports reveals that investigations under this heading are to ensure the viability of a project. Factors of interest to the Board include the source and method of capital investment, the name and reputation of financial advisors consulted, the existence or necessity of short-term "bridge" financing, and whether or not the economic viability of the project is contingent on such variables as market price, availability of feedstock and security of fuel source. A standard condition imposed by the Board in any permit is that the permitee satisfy the Board, prior to commencement of construction, that financial arrangements have been completed.

\section{Plans for Government or Public \\ Participation in the Project}

The Board's inquiry into these matters is for the purpose of ensuring that the project will be in the provincial public interest. Part of this public interest is to ensure that Albertans, and other Canadians, be given an opportunity to participate in the project financially or otherwise. Accordingly, the Board requires details of the applicant's ownership, the availability of its

55. The Board made its own estimate of market distribution in Report 77-C and commented, further, that the lack of firm benzene contracts was reasonable as final marketing plans would be dependent on the location of the benzene derivative plant.

56. Report 75-F, at 6-19. 
shares on the stock market and from other sources, and disclosure of any other plans allowing participation or requiring government financing or support. This last matter is a subject upon which the Board must report to the Alberta government for its consideration and includes such things as grants, special tax concessions and the need for special protectionist legislation. ${ }^{37}$

7. The Proposed Location of the Project

The policy of the provincial goverment is to encourage the development of a broad-based, decentralized, petrochemical industry but, locating a worldscale, petrochemical complex in or near medium- or small-sized municipalities places a great strain on such a community's socio-conomic infra-structure. The Board examines the adequacy and availability of community services within the area, in light of the government's desire to decentralize industrial development within Alberta. ${ }^{88}$

Topics of interest to the Board include the ability of the community to provide social services, utilities, housing, and the like; a discussion of other possible project locations, together with an explanation of the advantages and disadvantages of each; and a description of the availability of water, power, transportation, labour, raw materials and fuel. Marketing plans and a description of existing or proposed related industrial development should also be included. Further, should the applicant have plans to participate in community development or contribute to special projects, they should be detailed and communicated to the Board.

Preparation of a report on the possible socioeconomic impact of a project may be an arduous task but, it is submitted, one worth the effort. First, it establishes lines of communication with the community and demonstrates concern for local residents. Secondly, it may reveal previously undisclosed problems and allow community input or their resolution. Lastly, it may serve as the basis for continuing local input upon completion of the project.

\section{Management and Control of the Project}

The purpose of the Board's investigation in this area is to determine the situs of the project's decision making authority. Accordingly, the Board requires details of: the project's senior management structure; the nature and method of production and market policy planning; the method of delegating responsibility in projects where more than one corporate entity is involved; and the location of its head office and the composition and citizenship of its board of directors. Requirement of this information is demonstrative of the fact that the Board attempts to retain management control within Canada and preferably within Alberta. ${ }^{50}$

\section{Manpower Requirements}

The Board wishes to be informed of the numbers and skills of individuals employed in each phase of design, construction and operation of a project.

57. Requests for protective legislation have been made by the various applicants for pentanes plus usage. It should also be noted that the Board considers the availability of shares on a stock exchange to be of little participatory advantage to Albertans: See Report 75-N, at 8-22.

58. Report 75-F, at 6-24.

59. In Report 75-N, the Board suggests that the Lieutenant-Governor in Council may wish to condition the permit to ensure that maximum controls are maintained in Canada and Alberta. 
This information, in past applications, has been charted to show the percentage of skilled, unskilled, semi-skilled, management, professional and administrative personnel employed in each phase. The Board has generally concluded that it will not question manpower requirements as the applicant is in the best position to determine this information.

\section{Any Government Support Required}

This topic overlaps, to some extent, with Subsection 6, above. As previously mentioned, the Board requires an indication by the applicant of any direct or indirect governmental support through such means as the expansion and improvement of community services, subsidization of transportation rates, rebates and protectionist pricing policies or legislation.

\section{Social Impact Resulting from the Project}

This matter is related to and discussed in Subsection 7 above.

\section{The Environmental Impact}

Section 2(d) of The Energy Resources Conservation Act charges the Board with the duty "to control pollution and ensure environment conservation in the exploration for, processing, development and transportation of the energy resources and energy" in Alberta. ${ }^{60}$ As part of this duty, the Board requires that an applicant for an industrial development permit state the status of requisite permits, licences and approvals under Alberta's environment legislation and document the nature and quantity of waste materials that the project will discharge into the environment. The Board also requires a statement of the means by which these discharges will be controlled.

\section{Status of Other Authorizations Required}

In addition to authorizations required by the Department of the Environment, the Board is interested in the status of approvals required for such things as the location of plant facilities, pipeline depths, utility requirements, zoning or development, building standards, water diversion and approvals required by other legislation. Provision of this information assures the Board that the applicant has made timely application for all requisite approvals and allows the Board a means to ensure that all necessary approvals have been contemplated.

\section{Related Industrial Development}

Industrial development related to an applicant's project can be either existing or proposed. If the project is to form part of an integrated petrochemical scheme, then the Board wishes to be informed of the projects placed in that scheme. This information will normally be contained in the applicant's processing details. Similarly, a project which is but one part of an integrated scheme of development must be examined in light of downstream planning objectives. The Board is aware that such plans may be proprietary in nature but even a general statement of intention will be of assistance in assessing the project's viability and contribution to the Alberta public interest. 


\section{Other Matters}

The Board, in each of its reports to date, has commented on permit length and transferability: ${ }^{61} \mathbf{6 2}$

The Board believes that the term of an industrial development permit should be long enough to provide a payout of the necessary capital investment; but it should also have regard for the availability of the supply of gas or gas products to be used as a raw material or fuel for the proposed project and for the possibility of using an alternative raw material or fuel. The Board does not consider that a permit should be issued for a term longer than that requested by the applicant.

The Board finds that any permit issued should contain a condition that would require the permitee to seek permission from the Board before assigning the permit to others or before releasing from his control the operations of the plant.

\section{CONCLUSIONS}

To the writer's knowledge, the requirement of obtaining an industrial development permit for the use of a hydrocarbon in an industrial project is unique to Alberta and, possibly, to North America. Alberta's abundant resources of oil, gas and coal together with the Government's stated policy of encouraging decentralized industrial development make this Province a most attractive location for the development of worldscale petrochemicalbased industries. Undoubtedly, Alberta will become a Canadian centre for processing and manufacturing within the immediate future.

Alberta's "industrial revolution" began with the construction of the Alberta Gas Ethylene Company's integrated ethylene monimer plant in Red Deer, Alberta. Without slighting the significance of existing petrochemical complexes within the province, it is submitted that the Alberta Gas Ethylene project will be but the first of many projects whose products and services will cover the entire spectrum of the petrochemical industry. However, these new industries will be developed only under the close scrutiny and control of the Provincial government and, consequently, it is imperative that petrochemical concerns, and their counsel, are conversant with regulatory procedures such as applications for industrial development permits.

Similarly, the requirement of an industrial development permit is not restricted solely to new projects. Existing facilities seeking to expand or modify their operations will also be affected should such expansion or modification take it outside the class of exemptions provided by (7) and (7.1) of Section 42. For example, Canada Cement Lafarge Ltd. made recent application to the Board to expand and modify its cement plant at Exshaw, Alberta. The proposal involved an increase in the plant's use of natural gas as a fuel and required that an industrial development permit be obtained for that purpose. At a public hearing of the matter, intervenors strongly objected to the continued use of gas and proposed that the cement plant opera-

61. Report 75-F, at 72. Addenda: In Report 78-H, Canada Cement Lafarge Ltd. applied for a permit term of 35 years. However, the Board's concern for long-term availability of natural gas and its increasingly strong desire to have Alberta's coal resources commercially employed within the province resulted in a decision to award Canada Cement Lafarge Ltd. a permit term of only 7 years. Possible extensions to the permit will be contingent on the technological and economic feasibility of converting Canada Cement Lafarge Ltd.'s Exshaw facility to coal.

62. Id., at 8-10. 
tions be converted to a coal process. ${ }^{63}$ Future hearings, it is submitted, with issues involving the technological feasibility of using coal in an operation are likely to occur given the rising cost of both fuel oil and gas and the expected developments in coal recovery and fractionation techniques.

The industrial development permit is a new and relatively untried method of supervising and regulating industry. The procedural wrinkles have yet to be ironed out but it is apparent that both industry and the Board face a great number of potential problems.

The first problem, an evidentiary one, is proving that there are sufficient hydrocarbons available in the Province to allow for the development of a project when there are as many forecasts as there are forecasters. Many of the areas investigated by the Board, in determining whether or not an industrial development permit should issue, are so nebulous that they can neither be characterized nor defined.

Second, as hydrocarbon reserves decline, or when specific hydrocarbons become limitedly available, a system of usage priority must be developed. The lack of such priorities, and the absence of a mechanism for establishing such priorities, introduces an intolerable degree of uncertainty in long range corporate and regulatory planning. This is further complicated by the fact that neither the Board nor industry can predict a shortage of any specific hydrocarbon with any degree of accuracy. Nor can they foresee technological advances which may result in unprecedented demands for specific hydrocarbons or hydrocarbon constituents.

Third, government policy relating to petrochemical developments is liable to change without notice. By way of example, the anhydrous ammonia plants applied for in Report 75-F have yet to receive the approval of the LieutenantGovernor in Council due, it is submitted, to the restructuring of natural gas prices as outlined in Report 75-F-A. On the other hand, it is possible that a project in accord wth government policy and favour could be exempted from the requirement of an industrial development permit by application of subsection (8) of Section 42. In any industrial development permit, there is also the possibility that government policy concerns may be incorporated into an industrial development permit by the imposition of permit conditions pursuant to subsection (6)(b) of Section 42. It is even possible that a project could be "killed" or gelded by the imposition of harsh and unrealistic permit conditions.

63. Application No. 780056, Canada Cement Lafarge Ltd. was heard by the Board at a public hearing in Calgary, Alberta, on April 3rd and May 4th, 1978. At the time of writing, no decision has been rendered in this matter. Addenda: Board Report 78-H has since issued. The Report contains no new information insofar as it relates to the Board's method of assessing an application for an industrial development permit but is noteworthy in a number of respects. First, although the Board concludes there are sufficient gas reserves to allow Canada Cement Lafarge Ltd. to use natural gas as a fuel source throughout its requested 35 year permit, a permit term of only 7 years was granted. The reasoning of the Board is that gas and coal are comparatively efficient fuels in the production of cement and it is only a matter of present day economics which tip the scale in favour of using natural gas. Second, the Board, through any permit issues, will require Canada Cement Lafarge Ltd. to continue to investigate and report to the Board on the feasibility of converting its Exshaw, Alberta operation to a coal-fuel base. In effect, the Board will require Canada Cement Lafarge Ltd. to prove that coal is economically inferior to natural gas before renewing its permit for the use of natural gas beyond the initial 7 year period. Such proof must be sub. mitted to the Board 24 months in advance of any requested renewal. Lastly, the Board has, by this decision, demonstrated an unequivocal intention to require the use and upgradig of Alberta's coal reserves. 
Lastly, there are a host of practical problems associated with the application for and hearing of an industrial development permit. Commissioning studies, locating and briefing witnesses, preparing documentation, supplying deficiency returns, dealing with intervenors' concerns and presenting the application at a Board hearing are all time consuming and expensive endeavours. While the procedures are often familiar to corporate concerns, normally regulated by the Board, the requirement of an industrial development permit will increasingly bring concerns, with which there is no previous experience, into the application and hearing process. Uncertainty and unfamiliarity will most certainly result in confusion, delay and expense in obtaining requisite governmental approval. Similarly, the Board's lack of experience in the diversified fields now subject to the requirement of an industrial development permit will tend to increase the time required for approvals.

Clearly, corporate management will approach an application for an industrial development permit with some trepidation. However, proper preparation of an application and familiarity with the Board's concerns and procedures will undoubtedly put to rest many fears and speed the process. While this article will not serve as a basis for a successful application to the Board, it is the writer's hope that it may be of some assistance to those faced with such a task. 


\section{ENERGY RESOURCES CONSERVATION BOARD}

Calgary Alberta

TO: All Oil and Gas, Oil Sands, and Coal Operators, Major Energy Resource Purchasers, Energy Resource Transmission Companies, Chemical Companies, Major Industrial and Manufacturing Companies and Certain Others

\section{APPLICATIONS UNDER THE OIL AND GAS CONSERVATION ACT FOR INDUSTRIAL DEVELOPMENT PERMITS}

This interim directive supersedes ID 74-1 issued $10 \mathrm{June} 1974$. It outlines changes made to The Oil and Gas Conservation Act and The Coal Conservation Act respecting the authorization now required by operators to use energy resources in an industrial or manufacturing operation.

\section{INTRODUCTION AND BACKGROUND}

In the spring of 1974, the Legislative Assembly of Alberta replaced s. 42 of The Oil and Gas Conservation Act (hereinafter referred to as the Act) with a new s. 42 which provided that no gas or gas product produced in Alberta shall be used as raw material or fuel in the production of carbon black, ammonia, urea, ethanol, methanol, or any petrochemical product unless the Board, upon application, has granted a permit authorizing such use. The permit authorizing the use of gas or a gas product is known as an Industrial Development Permit. By Energy Resources Conservation Board Interim Directive No. ID 74-1 the Board set out its requirements for information in support of applications for Industrial Development Permits. Section 42 of the Act exempted from permit requirements the operators of relevant facilities which were in operation at the commencement of the amendment and the operators of planned new or expanding facilities, construction of which had commenced at the time of the amendment. Since the amendment to the Act, the Board has considered applications for the use of gas or a gas product for the production of ammonia, urea, ethylene, high density polyethylene, low density polyethylene, vinyl chloride monomer, methanol, ethylene oxide and ethylene glycols, benzene and other products.

Meanwhile at the fall 1975 session of the legislature, The Coal Conservation Act was amended by adding provisions requiring an Industrial Development Permit for the use of coal or a product derived therefrom as a raw material, reductant or fuel in an industrial or manufacturing operation. The Coal Conservation Act does not require permits for the operation of a power plant as defined in The Hydro and Electric Energy Act or where the quantity of coal used each year does not exceed 250,000 tons (227,000 tonnes). No applications for the industrial use of coal have been submitted so far and none appears imminent. Accordingly, the remainder of this letter pertains to the industrial use of energy resources, other than coal, governed by s. 42 of The Oil and Gas Conservation Act. 


\section{1976 AMENDMENT TO S. 42 OF THE ACT}

During the 1976 spring session of the Legislative Assembly of Alberta, s. 42 of the Act was further amended to specify that no energy resource produced in Alberta shall be used as a raw material or fuel in any industrial or manufacturing operation unless the Board, upon application, has granted a permit authorizing such use. Energy resource means gas, methane, ethane, propane, butanes, pentanes plus, condensate, crude oil, crude bitumen, or synthetic crude oil or any derivative of them. A copy of the amended s. 42 of the Act is included as Attachment 1. As a result of the 1976 amendment a permit is now required not only where gas or gas products are used, but also where condensate, crude oil, crude bitumen, or synthetic crude oil or any primary derivative of them is used as a raw material or fuel in any industrial or manufacturing operation. It is important to note that a permit is required where the energy resource is used in any industrial or manufacturing operation rather than specifically in the production of carbon black, ammonia, urea, ethanol, methanol, or any petrochemical product as was formerly the case. The industrial operations now covered by the legislation would include, but are not limited to, refineries, cement plants, and pulp and paper mills.

\section{OPERATIONS EXEMPT FROM PERMIT REQUIREMENTS}

While The Oil and Gas Conservation Act has been expanded to require Industrial Development Permits as discussed above, permits are not required:

(1) where the operations are approved under s. 38 of the Act (i.e., schemes for enhanced recovery of oil, processing of gas, underground storage of gas, reprocessing of gas), or s. 43 of the Act (i.e., schemes or operations for the recovery of oil sands, crude bitumen or products derived therefrom), or for power plants defined in The Hydro and Electric Energy Act,

(2) where the total quantity of energy in the energy resource used in any year as raw material and fuel does not exceed one trillion British thermal units $\left(1.1 \times 10^{15}\right.$ joules) and the quantity of energy in the energy resources used in that year as raw material does not exceed 100 billion British thermal units (1.1 x $10^{14}$ joules),

(3) for facilities of a sort not covered by the 1974 legislation and in operation as of 19 May 1976 if such facilities are not expanded and production of products from such facilities does not, on an annual basis, exceed the rate of production for the 12-month period ending 31 March 1976, and

(4) for new facilities or expansions to existing facilities where construction of the new or expanding facilities had commenced on or before 21 April 1976 , and the exemption continues only for so long as the operator uses the new or expanded facilities as they were being constructed on 21 April 1976 and does not thereafter alter the facilities to increase production capacity which results in an increase in the rate of use of any energy resource.

\section{BASIS FOR CONTROL OF VOLUME OF ENERGY RESOURCES USED IN EXEMPT OR PERMITTED FACILITIES}

The Board intends to concern itself only with the amount of energy resources used rather than the products manufactured in both exempt facilities and facilities for which permits are required. For certain facilities, whether exempted or permitted, flexibility may exist to use more than one energy resource as a raw material or fuel if no significant alterations are needed to the facilities. Examples of such facilities include refineries where crude oil, crude bitumen, synthetic crude oil, pentanes plus, and butanes might be used interchangeably as raw material or fuel or certain 
petrochemical operations where ethane, propane, or butanes might be used interchangeably as raw material or fuel. In such instances, the energy resources used will normally be regulated on a total basis rather than by component. To illustrate, the Board is prepared to limit the feedstock to a refinery or a petrochemical plant on a total volume basis (e.g., a total quantity, in barrels per day, of mixed refinery feedstock) and to allow the operator of the facility certain flexibility to vary the mix of that feedstock so long as the facilities do not require expansion or significant alterations to accept a variation in feedstock. Exceptions from the normal procedure of regulating feedstock on a total basis may be made with respect to any energy resource which the Board forecasts indicate a close balance between Alberta's requirements and available supply. In view of the Board's recent findings respecting certain applications to manufacture benzene and other byproducts it expects that pentanes plus may be in tight supply in a few years. It recognizes, however, that the list may vary with time. For these specific reserved energy resources, essentially no flexibility will exist in the maximum amount that may be used. The use of such resources will be limited to the extent that they have been used in the base year for exempted facilities or as specified in a permit. Where an operator wishes to vary the feedstock mix and use one of these reserved energy resources, a permit or permit amendment would be required. However, in such cases where the usage is for a short period of less than two or so years and where the resource is not in short supply for that period, the Board would not normally require a detailed application and would handle the matter in a routine fashion without hearing.

\section{REPORTING ON EXISTING AND \\ NEW OR EXPANDING FACILITIES}

In order to obtain details concerning those facilities which are exempt from Industrial Development Permit requirements, the Board requests that all persons currently operating facilities or constructing new facilities within the province which were in operation or under construction on 21 April 1976 and which use or will use an energy resource in an industrial or manufacturing operation as raw material and fuel in quantities in excess of that described in paragraph 3(2) report to it respecting such facilities not later than 31 October 1977. Plants which use gas or gas products and have reported in response to the Board's request in Interim Directive No. ID 74-1, dated 10 June 1974 , need not report again.

(a) Existing Facilities Which Were in Operation on 21 April 1976

The report on existing facilities should contain the following:

i a description of the ownership and location of the facilities,

ii a general description of the facilities, including a brief description of the process and the products to be produced,

iii a list by type and heating value of the raw material and fuel rates for the 12-month period ending 31 March 1976, and

iv the total production of each product during the 12-month period ending 31 March 1976.

While (a)iv above requests data on the products produced in the base period, the Board does not intend to concern itself with the amount of the specific products to be manufactured in the future.

(b) New or Expanding Facilities Which were Under

Construction on 21 April 1976 
For all new or expanding facilities not included in (a) above the report should include the following:

i a description of the ownership and location of the facilities,

ii a general description of the facilities, including a brief description of the process and the products to be produced,

iii a list by type and heating value of the intended volumes of raw material and fuel to be used,

iv the intended production rates for the various products, and

$v$ evidence that construction of the facilities had physically commenced by 21 April 1976. The Board considers that if a plant is to be exempt on the basis that its construction had commenced by 21 April 1976 there has to be significant construction of the plant on the plant site as of that date.

Following receipt of the previously described information, the Board will prepare and publish an up-to-date list of those industrial manufacturing operatings using energy resources for purposes described in s. 42 of The Oil and Gas Conservation Act which are exempt from the Industrial Development Permit requirements.

\section{REQUIREMENTS FOR PERMIT APPLICATIONS}

Attachement 2 outlines the requirements of the Board for information in support of applicationns for Industrial Development Permits. It is expected that the Oil and Gas Conservation Regulations will be amended to incorporate these requirements. The Board's consideration of applications for permits will normally involve a public hearing. In all cases, applications and information in support thereof will become public documents and will be available for perusal in the Board's offices in Calgary.

In making an application for an Industrial Development Permit, fifteen copies of the application and information and particulars required in support thereof shall be filed with the Board at its Calgary office. The Board will provide copies of the application to the Department of Business Development and Tourism, the Department of Energy and Natural Resources, and the Department of the Environment. If the application results in the granting of an Industrial Development Permit, later applications under The Water Resources Act, The Clean Water Act, The Clean Air Act and The Land Surface Conservation and Reclamation Act will be required, as appropriate, by the Department of the Environment.

If you have further questions respecting this matter, please refer them to Mr. D. G. Pearson of the Board's Gas Department.

ISSUED at Calgary, Alberta on 29 July 1977.

ENERGY RESOURCES CONSERVATION BOARD

V. MILLARD

Vice Chairman

Attachments 


\section{ATTACHMENT 1 to ID-OG 77-1}

42. (1) In this section,

(a) "energy resource" means gas, methane, ethane, propane, butanes, pentanes plus, condensate, crude oil crude bitumen or synthetic crude oil, or any primary derivative of any of them;

(b) "gas product" means any constituent of gas extracted by processing including methane, ethane, propane, butanes, and pentanes plus but not including sulphur or any sulphur compound.

(2) No energy resource produced in Alberta shall be used in Alberta as a raw material or fuel in any industrial or manufacturing operation unless the Board, upon application, has granted a permit authorizing such use for that purpose in accordance with this section.

(2.1) Notwithstanding subsection (2), a permit under this section is not required where

(a) the industrial or manufacturing operation is wholly in performance of a scheme or operation approved under section 38 or section 43 or is a power plant as defined in The Hydro and Electric Energy Act, or

(b) the total quantity of energy in the energy resource used in any year as a raw material or fuel or both in the industrial or manufacturing operation does not exceed one trillion British thermal units, and the quantity of energy in the energy resources used in that year as a raw material in the industrial or manufacturing operation does not exceed one hundred billion British thermal units.

(3) Upon receipt of an application pursuant to subsection (2) together with any information prescribed or required by the Baord, the Board may,

(a) if so authorized by the Lieutenant-Governor in Council, grant a permit for the use of the energy resource proposed in the application, or

(b) refuse the application.

(4) The Board may hold a hearing with respect to an application under this section.

(5) The Board shall not grant a permit under this section unless in its opinion it is in the public interest to do so having regard to, among other considerations,

(a) the efficient use without waste of the energy resource, and

(b) the present and future availability of hydrocarbons in Alberta.

(6) A permit granted pursuant to this section

(a) shall be referred to as an "industrial development permit",

(b) shall be in the form prescribed by the order of the LieutenantGovernor in Council authorizing the granting of the permit and shall be subject to any terms or conditions prescribed by the Lieutenant-Governor in Council,

(c) shall authorize the use of the energy resource for the purpose or purposes prescribed in the permit,

(d) may prescribe the term for which the permit is granted,

(e) may prescribe the maximum volumes of the energy resource that may be used during the term of the permit, and 
(f) shall be subject to any other terms and conditions contained in the permit.

(7) A person is exempt from the operation of this section

(a) if, on June 6th, 1974, he is using gas or a gas product in Alberta as a raw material or fuel in the production of carbon black, ammonia, urea, ethanol, methanol or any petrochemical product but the exemption under this clause continues only for solong as that person

(i) uses production facilities for that purpose that are in existence on June 6th, 1974 and continues such production at an annual rate of production not exceeding the rate of production for the 12-month period ending April 30, 1974, or

(ii) uses production facilities for that purpose that are in existence on June 6th, 1974 but which have been added to, extended or altered to increase production capacity where the construction of the addition, extension or alteration commenced on or before May 16,1974;

(b) if he intends to use gas or a gas product in Alberta as a raw material or fuel in the production of carbon black, ammonia, urea, ethanol, methanol, or any petrochemical product and had commenced the construction of production facilities for that purpose on or before May 16, 1974, but the exemption under this clause continues only for so long as that person uses the production facilities that were under construction on May 16, 1974 and does not thereafter construct any addition, extension to or alterations of those facilities to increase production capacity which results in an increase in the rate of use of the gas or gas products;

(c) if he is so exempted by the regulations under subsection (8).

(7.1) A person, other than one described in subsection (7), is exempt from the operation of this section

(a) if, at the commencement of this subsection, he is using an energy resource produced in Alberta as a raw material or fuel in any operation of the kind referred to in subsection (2), but the exemption provided by this clause continues only for so long as that person

(i) uses production facilities for that purpose that are in existence at the commencement of this subsection and continues such production at an annual rate of production not exceeding the rate of production for the 12-month period ending March 31, 1976, or

(ii) uses production facilities for that purpose that are in existence at the commencement of this subsection but which have been added to, extended or altered to increase production capacity where the construction of the addition, extension or alteration commenced on or before April 21,1976, but the exemption under this subclause continues only for as long as that person uses the production facilities as they were being added to, extended or altered on April 21, 1976 and does not thereafter construct any further addition, extension or alteration of those facilities to increase production capacity which results in an increase in the rate of use of an energy resource; 
(b) if he intends to use an energy resource produced in Alberta in an operation of the kind to which clause (a) applies, and had commenced the construction of production facilities for that purpose on or before April 21, 1976, but the exemption under this clause continues only for as long as that person uses the production facilities that were under construction on April 21, 1976 and does not thereafter construct any addition, extension to or alteration to those facilities to increase production capacity which results in an increase in the rate of use of an energy resource;

(c) if he or his industrial or manufacturing operation is so exempted by the regulations under subsection (8).

(8) The Lieutenant-Governor in Council may make regulations exempting from the application of this section

(a) any person or class of persons, or

(b) any industrial or manufacturing operation or any part thereof or any class of industrial or manufacturing operation.

\section{ATTACHMENT 2 to ID-OG 77-1}

\section{REQUIREMENTS OF THE BOARD FOR INFORMATION IN SUPPORT OF AN APPLICATION FOR AN INDUSTRIAL DEVELOPMENT PERMIT}

1. General Description. (Further details respecting the required information are given in items (a), (b), (c), and (d) of the attached document.)

2. Background of Owners and Participants. (Further details are given in items (e) and (f).)

3. Process Details. (Further details are given in item (g).)

4. Raw Materials and Fuels. (Further details are given in items $(\mathrm{h}),(\mathrm{i}),(\mathrm{j}),(\mathrm{k})$, and (1).)

5. Upgrading of Resources. (Further details are given in item (m).)

6. Marketing Plans. (Further details are given in item (n).)

7. Capital Costs and Operating Expenditures. (Further details are given in items (o) and (p).)

8. Employment. (Further details are given in item (q).)

9. Economic Viability and Financing. (Further details are given in item (r).)

10. Ownership and Control Policy. (Further details are given in items (s) and (t).)

11. Related Industrial Development. (Further details are given in item (u).)

12. Required Government Support. (Further details are given in item (v).)

13. Environmental Impact and Zoning Authorizations. (Further details are given in items $(w)$ and $(x)$.)

14. Overall Impact on Alberta Economy and Public Interest. (Further details are given in items $(y)$ and $(z)$.) 


\section{DETAILS OF INFORMATION REQUIRED IN SUPPORT ON AN} APPLICATION FOR AN INDUSTRIAL DEVELOPMENT PERMIT

\section{General Description}

(a) A general statement of the scope of the proposed project.

(b) The location proposed for the project, possible alternative locations and a discussion of the reasons for the choice of the location.

(c) The identity of the owners of and participants in the proposed project.

(d) The term of the applied for permit.

Background of Owners and Participants

(e) A general statement of the ownership and control of each of the owners and participants referred to in item (c).

(f) A statement of the relevant technical, financial, and marketing background of each of the owners of and participants in the proposed project.

\section{Process Details}

(g) A description of the products to be produced and the processes involved in the proposed project, together with flow sheets, material balances and energy balances. Also, measurement details relating to the energy resources to be delivered to the proposed project and any emissions to the atmosphere of portions of the energy resources. (The description of products should include reference to anticipated minor changes in product runs which might occur from time to time.)

Raw Materials and Fuels

(h) A year-by-year forecast of the quantities of each of the raw materials and fuels required for the proposed project and a statement respecting the flexibility of the proposed project to use alternative raw material or fuel.

(i) A statement respecting any form of energy other than energy resources described in the Act which would be utilized by the proposed project including the source and quantity of such energy.

(j) A statement of the manner in which each of the required raw materials and fuels will be obtained, including the source, the intended supplier and the arrangements for the necessary facilities to transport the materials to the location of the proposed project. (The statement should include information as to how the energy resource in question might otherwise be utilized or disposed of.)

(k) Details or a general statement of the price to be paid for each of the raw materials and fuels required for the proposed project.

(1) Evidence respecting the availability of a supply of the required raw materials and fuel including a forecast of the Alberta supply and of the other Alberta requirements for any energy resource required. (Reference may be made to recent Board publications respecting reserves and requirements of energy resource.)

\section{Upgrading of Resources}

(m) Evidence respecting the extent of and future prospects for further upgrading in Alberta of the energy resource required for or the products to be produced by the proposed projects, including, where possible, a time schedule of planned upgrading. 
(n) Ageneral statement of marketing plans, including the location of intended markets, the method of transportation thereto, a projection of market prices for the products to be produced and a discussion relating the marketing plans to the overall Alberta, Canada, North America, and world supply and requirements situation.

Capital Costs and Operating Expenditures

(o) Detailed estimates, including a time schedule, of the capital investment necessary to the proposed project.

(p) Detailed estimates, including a time schedule, of anticipated operating expenditures.

Employment

(q) An estimate and a time schedule of the numbers of workers that would be employed in each of the construction and operating phases of the proposed project for the categories of unskilled workers, tradesmen, technicians, and professionals, and a discussion of the source and availability of the required workers.

Economic Viability and Financing

(r) Evidence respecting the economic viability of the proposed project and an outline of the proposed method of financing the project.

Ownership and Control Policy

(s) A statement of policy of the owners and participants respecting the provision of opportunities for Albertans and other Canadians to participate in the ownership of the proposed project.

(t) A statement of policy of the owners and participants respecting the location of senior decision making and personnel related to management, marketing administration and research affecting the proposed project.

Related Industrial Development

(u) Evidence of the extent of and the prospects for related industrial development in Alberta resulting from the proposed project.

Required Government Support

(v) A statement respecting any Government support and services which may be required.

Environmental Impact and Zoning Authorizations

(w) A broad statement of the environmental impact of the proposed project. (Details of the environmental impact will be required later by the Department of the Environment.)

(x) A statement concerning the status of any necessary zoning or related authorizations.

Overall Impact on Alberta Economy and Public Interest

(y) Detailed evidence of the impact of the proposed project on the Alberta economy, categorized as the impact of the project itself and that resulting from expected downstream development, including the impact of capital and operating expenditures for labour, services, materials and supplies, payments of taxes and royalties, and incorporating any appropriate economic multiplier effect. In certain circumstances the Board may require a cost-benefit analysis.

(z) A summary statement of the overall desirability in the Alberta public interest of the proposed project. 
APPENDIX "B"

SOURCE: ERCB Board Report 75-N at 1-5

TABLE 1-1

Petrochemical Facilities (Excluding Fetilizer Plants) Exempt From Section 42 of The Oil and Gas Conservation Act

A. Existing projects that were in operation as of June 6,1974 and where no expansion of the facilities was taking place.
Company
Location
Products

1. Canadian Industries County of Strathcona Polyethylene Limited

2. Cancarb Limited Medicine Hat

3. Dow Chemical of Fort Saskatchewan Canada, Limited

Thermal Carbon

Blacks

Ethylene Glycol

Amines

Herbicides

4. Thio-Pet Chemicals Fort Saskatchewan Limited

Carbon Disulphide

Hydrogen Sulphide

B. Existing projects that were in operation as of June 6, 1974 and where expansion of the facilities had commenced prior to May 16, 1974. (The exemption applies to both the existing facilities and the expansion.)

Company

1. Celanese Canada Limited
Location

Edmonton
Products

Acetic Acid

Acetic Anhydride

CCS - 500

Propionic Acid

CCS -972

CCS -973

Chemstor

Cellulose Acetate Flake

Cigarette Tow

Arnel

Formaldehyde

Pentaerythritol

C. New projects where construction had commenced prior to May 16, 1974 .

Company

1. Alberta Gas

Chemicals Ltd.
Location

Medicine Hat Plant No. 1 Methanol

The fertilizer plants omitted from this table all produce ammonia and urea and are exempted as follows:

- Alberta Regulation 220/74 - Cominco Ltd. at Carseland, Alberta, and Western Co-operative Fertilizers Limited at Medicine Hat, Alberta;

- Alberta Regulation 248/74 - Sheritt Gordon Mines Limited at Fort Saskatchewan, Alberta;

- Alberta Regulation 240/75 - Canadian Fertilizers Limited at Medicine Hat, Alberta. 


\section{APPENDIX “C”}

(i) ERCB Report 75-F, In the Matter of an Application of PanCanadian Petroleum Limited and In the Matter of an Application of Alberta Ammonia Ltd., both under Section 42 of The Oil and Gas Conservation Act, April 1975 (Cited herein as 75-F).

(ii) ERCB Report 75-F-A, In the Matter of an Application of PanCanadian Petroleum Limited and In the Matter of an Application of Alberta Ammonia Ltd., both under Section 42 of The Oil and Gas Conservation Act, October 1975 (Cited herein as 75-F-A).

(iii) ERCB Report 75-G, In the Matter of an Application of Canadian Fertilizers Limited under Section 42 of The Oil and Gas Conservation Act, May 1975 (Cited herein as 75-G).

(iv) ERCB Report 75-N, In the Matter of an Application of The Alberta Gas Ethylene Company Ltd., DuPont of Canada Limited, Dow Chemical of Canada, Limited and Canadian Industries Limited, all under Section 42 of The Oil and Gas Conservation Act, November 1975 (Cited herein as 75-N).

(v) ERCB Report 76-B, In the Matter of an Application of Dow Chemical of Canada, Limited under Section 42 of The Oil and Gas Conservation Act, April 1976 (Cited herein as 76-B).

(vi) ERCB Report 76-E, In the Matter of an Application of Alberta Gas Chemicals Ltd. under Section 42 of The Oil and Gas Conservation Act, July 1976 (Cited herein as 76-E).

(vii) ERCB Report 76-I, In the Matter of an Application of Dow Chemical of Canada, Limited under Section 42 of The Oil and Gas Conservation Act, October 1976 (Cited herein as 76-I).

(viii) ERCB Report 77-C, In the Matter of an Application of Alberta Energy Company Ltd., Hudson's Bay Oil and Gas Company Limited, Mitsubishi Petrochemical Company Limited and Mitsubishi Corporation and In the Matter of an Application of the Alberta Gas Trunk Line Company Limited, Dow Chemical of Canada, Limited and Alberta Gas Chemicals Ltd., both under Section 42 of The Oil and Gas Conservation Act, February 1977 (Cited herein as 77-C).

(ix) ERCB Report 77-H, In the Matter of an Application of Turbo Resources Limited under Section 42 of The Oil and Gas Conservation Act, December 1977 (Cited herein as 77-H).

(x) ERCB Report 78-C, In the Matter of an Application of Gulf Oil Canada Limited under Section 42 of The Oil and Gas Conservation Act, May 1978 (Cited herein as 78-C).

(xi) ERCB Report 78-H, In the Matter of an Application of Canada Cement Lafarge Ltd. under Section 42 of The Oil and Gas Conservation Act, August 1978 (Cited herein as 78-H). 